\title{
Discrete control of unified power flow controller for stability improvement
}

\author{
S. Krishna ${ }^{\mathrm{a}, *}$, K.R. Padiyar ${ }^{\mathrm{b}}$ \\ ${ }^{a}$ M.S. Ramaiah Institute of Technology, Department of Electrical and Electronics Engineering, \\ M.S.R.I.T. Post, Bangalore 560054, India \\ ${ }^{\mathrm{b}}$ Indian Institute of Science, Department of Electrical Engineering, Bangalore 560012, India
}

\begin{abstract}
The emerging flexible ac transmission system (FACTS) controllers are considered to be suitable for transient stability control due to their speed and flexibility. In this paper, a control strategy is developed to achieve maximal improvement in transient stability and damp the rotor oscillations using unified power flow controller (UPFC). The control strategy involves maximization and minimization of power flow in a line. In general, this involves the solution of a constrained optimization problem at each step to determine the voltage and current injected by the UPFC. For the special case of a lossless symmetrical line, when the UPFC is located at the midpoint of the line, analytical solution can be derived. The control strategy can be extended to multimachine system and maximizing and minimizing power flow on a critical line can improve transient stability. The control strategy is evaluated by simulation studies.
\end{abstract}

Keywords: Maximization (minimization) of power; Transient stability control; Unified power flow controller

\section{Introduction}

Control by changing the network parameters is an effective method of improving transient stability. Flexible ac transmission system (FACTS) controllers due to their rapid response are suitable for transient stability control since they can bring about quick changes in the network parameters. Transient stability control involves changing the control variables such that the system state enters the stability region after a large disturbance.

FACTS controllers based on voltage source converters use turn off devices like Gate Turn-Off Thyristors (GTO) [1]. The magnitude and angle of the fundamental frequency voltage injected by the converter is varied by controlling the switching instants of the GTO devices. These type of FACTS controllers have the advantages of reduced equip-

\footnotetext{
* Corresponding author.

E-mail addresses: krishna_sme@yahoo.com (S. Krishna), krpyar@ee.iisc.ernet.in (K.R. Padiyar).
}

ment size and improved performance compared to variable impedance type controllers. Static VAR compensator (SVC) and thyristor controlled series capacitor (TCSC) are variable impedance type controllers. SVC is a shunt controller and TCSC is a series controller. Static compensator (STATCOM), static synchronous series compensator (SSSC) and unified power flow controller (UPFC) are voltage source converter based controllers. STATCOM is a shunt controller and SSSC is a series controller. UPFC consists of a shunt converter and a series converter, which have a common dc capacitor as shown in Fig. 1 [2]. UPFC injects a series voltage and a shunt current. The series and shunt branches of UPFC can generate/absorb reactive power independently and the two branches can exchange real power; therefore, UPFC has three degrees of freedom.

The main function of FACTS controllers is control of voltage and power flow. In [3], a control strategy is proposed for UPFC in which the power flow in the line is regulated by control of series reactive voltage and the voltages at the two ports of UPFC are regulated by control of shunt reactive 


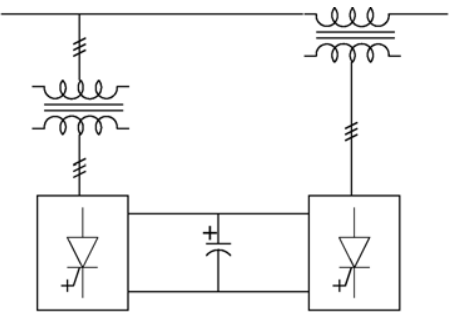

Fig. 1. Schematic diagram of UPFC.

current and series real voltage. In addition to power flow control and voltage regulation, FACTS controllers can be used for transient stability improvement and damping of power swings. Mihalic et al. [4] propose maximization of power using UPFC for improvement in transient stability of a single machine infinite bus (SMIB) system. Bian et al. [5] propose a control strategy to increase power transfer between two large areas during a contingency, using UPFC, while considering the operational constraints.

There are many control measures known as discrete supplementary controls, which are used for transient stability improvement [6]. These controllers do not operate continuously but are initiated following a large disturbance and are temporary in nature.

In this paper, a discrete control strategy is presented for UPFC in order to improve transient stability and damp the oscillations. The previously proposed methods of transient stability improvement and damping of oscillations using network controllers are applicable to braking resistors [7], switched series capacitors [8-10] and TCSC [11], which have a single control variable. The control strategy is not obvious in the case of UPFC, which has three independent control variables. The proposed control strategy involves both maximization and minimization of power flow in the line in which UPFC is located. An expression for power flow in the presence of UPFC is derived. The control strategy is applied to SMIB and multimachine systems.

\section{Control strategy}

In this section, a control strategy for transient stability improvement and damping the oscillations is developed for UPFC in a SMIB system shown in Fig. 2. The generator is represented by a voltage source $E_{1} \angle \zeta$ (in series with the

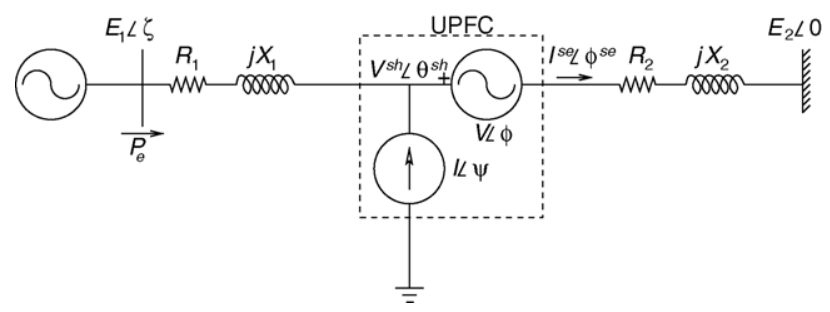

Fig. 2. SMIB system with UPFC. direct axis transient reactance, which is absorbed in the reactance $X_{1}$. This representation of generator is applicable for classical model and two-axis model if direct axis transient reactance $\left(x_{\mathrm{d}}^{\prime}\right)$ is equal to quadrature axis transient reactance $\left(x_{\mathrm{q}}^{\prime}\right)$. For classical generator model, $E_{1}$ is constant and $\zeta=\delta$, where $\delta$ is rotor angle. For two-axis model of generator with $x_{\mathrm{d}}^{\prime}=x_{\mathrm{q}}^{\prime}, E_{1} \angle \zeta=\left(E_{\mathrm{q}}^{\prime}+j E_{\mathrm{d}}^{\prime}\right) \mathrm{e}^{j \delta}$, where $E_{\mathrm{q}}^{\prime}$ is generator quadrature axis voltage and $E_{\mathrm{d}}^{\prime}$ is generator direct axis voltage. The UPFC is represented by a series voltage source $V \angle \phi$ and a shunt current source $I \angle \psi$. Neglecting losses, the real power constraint on the UPFC is given by the following equation:

$\Re\left[V^{\mathrm{sh}} \angle \theta^{\mathrm{sh}}(I \angle \psi)^{*}\right]=\mathfrak{R}\left[V \angle \phi\left(I^{\mathrm{se}} \angle \phi^{\mathrm{se}}\right)^{*}\right]$

Transient stability is improved by maximizing the electrical power $P_{\mathrm{e}}$ as soon as the disturbance is detected and then the rotor oscillations are damped by successively decreasing the decelerating and accelerating areas. The control strategy is developed using the power angle curves for the SMIB system, shown in Fig. 3; the generator is represented by classical model. There are three power angle curves corresponding to base power (with base or operating values of UPFC control variables), maximum power and minimum power. Power can be maximized and minimized by suitably selecting the values of UPFC control variables. $P_{\mathrm{m}}$ is the mechanical power input. Let $\delta_{\mathrm{s}}$ be the initial as well as the post-fault steady state rotor angle of the SMIB system. For a disturbance like a three phase fault at the generator terminals, the accelerating area is 'abcda'. Due to the kinetic energy stored in the rotor at the time of fault clearing, the rotor swings beyond $\delta_{\mathrm{cl}}$ (the rotor angle at the instant of clearing) and reaches a peak of $\delta_{\max }$ when the decelerating area 'defgd' is equal to the area 'abcda'. In order to minimize $\delta_{\text {max }}$, it is essential to maximize the electrical power. Thus ' $\mathrm{e}$ ' and ' $\mathrm{f}$ ' lie on the power angle curve corresponding to the maximum power flow in the line controlled by adjusting

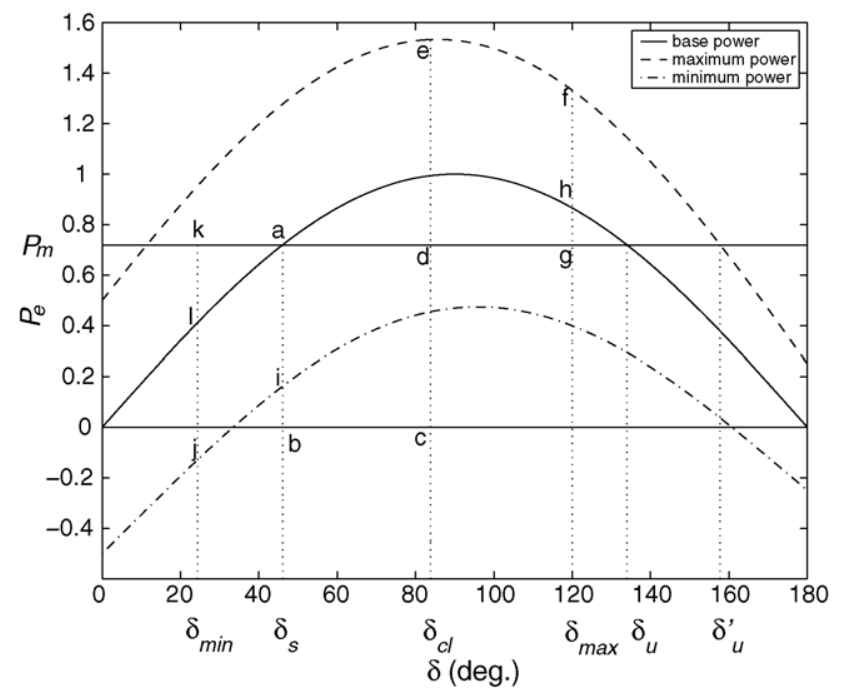

Fig. 3. Power angle curves. 
the UPFC variables $V, \phi$ and $I$ (it is to be noted that $\psi$ is a dependant variable constrained by equation (1)). At $\delta=\delta_{\max }$, $\frac{\mathrm{d} \delta}{\mathrm{d} t}=0$. For values of $\delta_{\max } \leq \delta_{\mathrm{u}}$, where $\delta_{\mathrm{u}}$ is the value of the rotor angle at the unstable equilibrium point corresponding to the post-fault steady state values of the UPFC variables, switching the UPFC variables to the operating values at the instant when $\delta=\delta_{\max }$, results in steering the rotor angle to the stable equilibrium value $\delta_{\mathrm{s}}$. When $\delta=\delta_{\mathrm{s}}, \frac{\mathrm{d} \delta}{\mathrm{d} t}$ is negative and is at the minimum. Switching the UPFC variables such that the power flow is minimum, results in reducing the undershoot of the rotor angle. The rotor angle reaches a minimum value of $\delta_{\min }$ such that the accelerating area 'aijka' is equal to the decelerating area 'ghag'. At $\delta=\delta_{\min }, \frac{\mathrm{d} \delta}{\mathrm{d} t}=0$ and switching the UPFC variables to the operating values at this instant results in steering the rotor angle to the stable equilibrium value. When $\delta=\delta_{\mathrm{s}}, \frac{\mathrm{d} \delta}{\mathrm{d} t}$ is maximum and the UPFC variables are switched such that the power flow is maximum. To summarize, both overshoot and undershoot of the rotor angle can be minimized if the power flow is maximized when $\delta>\delta_{\mathrm{s}}$, $\frac{\mathrm{d} \delta}{\mathrm{d} t}>0$ and power flow is minimized when $\delta<\delta_{\mathrm{s}}, \frac{\mathrm{d} \delta}{\mathrm{d} t}<0$.

When $\delta_{\mathrm{u}} \leq \delta_{\max } \leq \delta_{\mathrm{u}}^{\prime}\left(\delta_{\mathrm{u}}^{\prime}\right.$ is the value of the rotor angle at the unstable equilibrium point for maximum power), the UPFC variables cannot be switched to their operating values until $\delta$ reduces to $\delta_{\mathrm{u}}$ at which $P_{\mathrm{e}}^{\mathrm{pf}}=P_{\mathrm{m}}$, where $P_{\mathrm{e}}^{\mathrm{pf}}$ is the electrical power corresponding to the post-fault (base) case. At this point, $\frac{\mathrm{d} \delta}{\mathrm{d} t}<0$ and the potential energy $W_{\mathrm{p}}$ defined for the post-fault system reaches a maximum and $\frac{\mathrm{d} W_{\mathrm{p}}}{\mathrm{d} t}=0$.

$W_{\mathrm{p}}=\int_{\delta_{\mathrm{s}}}^{\delta}\left(P_{\mathrm{e}}^{\mathrm{pf}}-P_{\mathrm{m}}\right) \mathrm{d} \delta$

It is to be noted that even for $\delta=\delta_{\max }, \delta_{\max } \leq \delta_{\mathrm{u}}, \frac{\mathrm{d} W_{\mathrm{p}}}{\mathrm{d} t}=0$ as $\frac{\mathrm{d} \delta}{\mathrm{d} t}=0$.

The control strategy can be stated as follows:

(1) As soon as a large disturbance is detected, the control variables are selected such that the power is maximized.

(2) The control variables are switched to their operating values when $\frac{\mathrm{d} W_{\mathrm{p}}}{\mathrm{d} t}=0$ and $\frac{\mathrm{d} \delta}{\mathrm{d} t} \leq 0$.

(3) The control variables are selected such that the power is minimized when $\frac{\mathrm{d} \delta}{\mathrm{d} t}$ is at a minimum and $\frac{\mathrm{d} \delta}{\mathrm{d} t}<-\epsilon$.

(4) The control variables are switched to their operating values when $\frac{\mathrm{d} \delta}{\mathrm{d} t}$ becomes zero.

(5) The control variables are selected such that the power is maximized when $\frac{\mathrm{d} \delta}{\mathrm{d} t}$ is at a maximum and $\frac{\mathrm{d} \delta}{\mathrm{d} t}>\epsilon$. The procedure from step 2 is repeated.

The control action is disabled when the maximum value of $\left|\frac{\mathrm{d} \delta}{\mathrm{d} t}\right| \leq \epsilon$. Step 2 is applicable for both cases, namely $\delta_{\max } \leq \delta_{\mathrm{u}}$ and $\delta_{\mathrm{u}}<\delta_{\max } \leq \delta_{\mathrm{u}}^{\prime} ; \frac{\mathrm{d} W_{\mathrm{p}}}{\mathrm{d} t}=0$ when $P_{\mathrm{e}}^{\mathrm{pf}}=P_{\mathrm{m}}$ or $\frac{\mathrm{d} \delta}{\mathrm{d} t}=0$. The control strategy is applicable even if the post-fault operating point is not the same as the pre-fault operating point.

It is to be noted that the control strategy for UPFC is general. For FACTS controllers like SVC, TCSC, STATCOM and SSSC which have a single control variable, power is maximized when operating at the capacitive limit and power is minimized when operating at the inductive limit in the range $0<\delta<\pi$.

The control strategy is developed for classical model of the generator. The same control strategy can also be applied to a system with generator represented by detailed (two-axis) model. This is based on the fact that the potential energy given by Eq. (2) is applicable even for two-axis model of generator [12].

\section{Optimization of power with UPFC}

The UPFC is located in the transmission line as shown in Fig. 2. The generator power (objective function to be maximized or minimized) can be expressed in terms of the UPFC control variables $V, \phi, I$ and $\psi$ as follows:

$P_{\mathrm{e}}=c V \cos \phi+d V \sin \phi+f I \cos \psi+g I \sin \psi+l$

The real power constraint (equality constraint) on the UPFC is given by the following equation:

$$
\begin{aligned}
& m V^{2}+n I^{2}+o V \cos \phi+p V \sin \phi+q I \cos \psi \\
& +r I \sin \psi+t V I \sin (\psi-\phi)=0
\end{aligned}
$$

The expressions for the coefficients $c$ to $t$ are given in Appendix A.

The following constraints are imposed on the ratings of the series and the shunt converters:

$0 \leq V \leq V_{\max }$

$0 \leq I \leq I_{\max }$

\subsection{Lossless circuit}

For a lossless circuit $\left(R_{1}=R_{2}=0\right), m=n=t=0$; the real power constraint on the UPFC given by Eq. (4) can be written as follows:

$o V \cos \phi+p V \sin \phi+q I \cos \psi+r I \sin \psi=0$

The variable $\psi$ is eliminated using Eq. (7).

$\psi=\cos ^{-1}\left(-\frac{o V \cos \phi+p V \sin \phi}{I \sqrt{q^{2}+r^{2}}}\right)+\tan ^{-1}\left(\frac{r}{q}\right)$

The first term on the right-hand side has two values. The second term on the right-hand side has a unique value $\alpha_{1}$ such that $\sin \alpha_{1}=\frac{r}{\sqrt{q^{2}+r^{2}}}$ and $\cos \alpha_{1}=\frac{q}{\sqrt{q^{2}+r^{2}}}$. Substituting this expression for $\psi$ in Eq. (3), the following expression is obtained for power in terms of three control variables namely $V, I$ and $\phi$ :

$$
\begin{aligned}
P_{\mathrm{e}}= & \left(c-\frac{f q+g r}{q^{2}+r^{2}} o\right) V \cos \phi+\left(d-\frac{f q+g r}{q^{2}+r^{2}} p\right) V \sin \phi \\
& \pm \frac{g q-f r}{q^{2}+r^{2}} \sqrt{I^{2}\left(q^{2}+r^{2}\right)-(o V \cos \phi+p V \sin \phi)^{2}}+l
\end{aligned}
$$


This is the objective function to be maximized (or minimized) subject to the inequality constraints given by Eqs. (5) and (6). The Kuhn-Tucker conditions for optimal power are given by the following equations:

$\frac{\partial P_{\mathrm{e}}}{\partial V} V\left(V-V_{\max }\right)=0$

$\frac{\partial P_{\mathrm{e}}}{\partial I} I\left(I-I_{\max }\right)=0$

$\frac{\partial P_{\mathrm{e}}}{\partial \phi}=0$

The magnitudes of series voltage and shunt current injected by UPFC for maximum as well as minimum power are the limits $V_{\max }$ and $I_{\max }$, respectively, for all values of $\zeta$. If $E_{1}=E_{2}$ and $X_{1}=X_{2}$, for maximum power, $\phi$ and $\psi$ are obtained as linear functions of $\zeta$ given by the following equations:

$\phi=\frac{\zeta}{2}-\frac{\pi}{2}$

$\psi=\frac{\zeta}{2}-\frac{\pi}{2}, \quad 0<\zeta<\pi$

For minimum power, $\phi$ and $\psi$ are obtained as linear functions of $\zeta$ given by the following equations:

$\phi=\frac{\zeta}{2}+\frac{\pi}{2}$

$\psi=\frac{\zeta}{2}+\frac{\pi}{2}, \quad 0<\zeta<\pi$

If $X$ is the total reactance, $X_{1}=X_{2}=\frac{X}{2}$. Let $E_{1}=E_{2}=E$. Substituting the expressions for $\phi$ and $\psi$ given by Eqs. (13)-(16) in the Eq. (3), the expressions for maximum and minimum power are as given below:

$P_{\max }=\frac{E V_{\max }}{X} \cos \left(\frac{\zeta}{2}\right)+\frac{E I_{\max }}{2} \sin \left(\frac{\zeta}{2}\right)+\frac{E^{2} \sin \zeta}{X}$,
$0<\zeta<\pi$

$P_{\min }=-\frac{E V_{\max }}{X} \cos \left(\frac{\zeta}{2}\right)-\frac{E I_{\max }}{2} \sin \left(\frac{\zeta}{2}\right)+\frac{E^{2} \sin \zeta}{X}$,

$0<\zeta<\pi$

The power through the dc link (power transferred from the series branch to the shunt branch) for both maximum and minimum power for the special case $\left(E_{1}=E_{2}\right.$ and $\left.X_{1}=X_{2}\right)$ is as follows:

$P_{\mathrm{dc}}=\frac{V_{\max } I_{\max }}{2}, \quad 0<\zeta<\pi$

It can be seen that for this special case, the power through the dc link for maximum and minimum power depends only on the ratings of the shunt and series converters and does not depend on the system parameters.

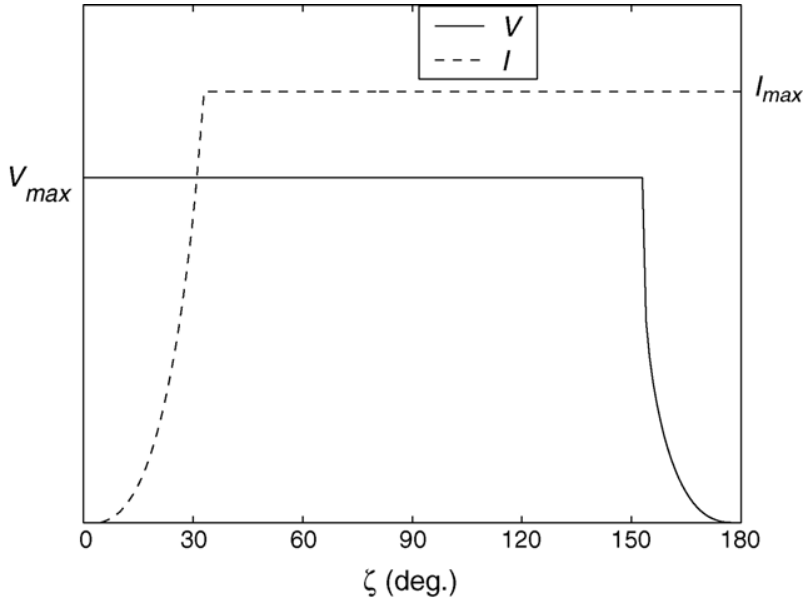

Fig. 4. Magnitude of series voltage and shunt current injected by UPFC for maximum power $(\mathrm{dc}$ power $=0)$.

If the power through the dc link is constrained to be zero, the series and the shunt branches inject reactive voltage and reactive current, respectively. The plot of the injected reactive voltage and reactive current for maximum power are shown in Fig. 4.

\section{Extension of control strategy to multimachine system}

The extension of the control strategy to multimachine system is based on the fact that when a power system becomes unstable, it initially splits into two groups. There is a unique cutset known as critical cutset consisting of series elements (connecting the two areas) across which the angle becomes unbounded [12]. The system can be represented as shown in Fig. 5. Locating the UPFC in one of these lines belonging to the critical cutset strengthens the system and improves transient stability.

The potential energy $W_{\mathrm{p}}$ can be expressed as follows [12]:

$W_{\mathrm{p}}=\sum_{k=1}^{n s} \int_{t_{o}}^{t}\left(P_{k}-P_{k \mathrm{~s}}\right) \frac{\mathrm{d} \delta_{k}}{\mathrm{~d} t} \mathrm{~d} t$

where $P_{k}$ is the power flow in the series element $k, P_{k \mathrm{~s}}$ the post-fault steady state value of $P_{k}, \delta_{k}$ the phase angle

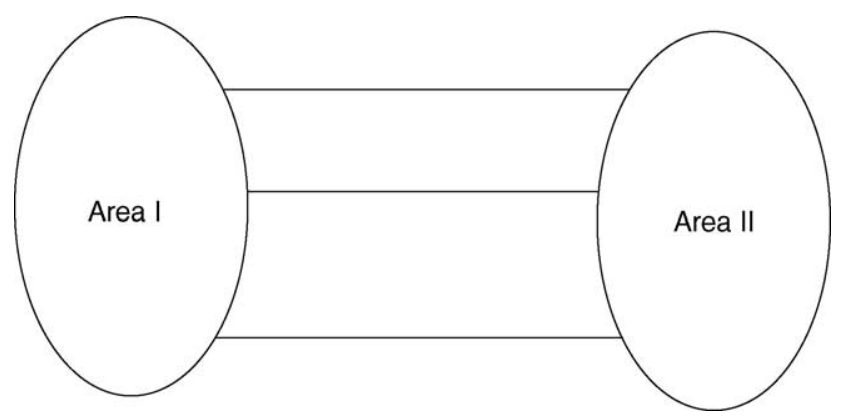

Fig. 5. Coherent areas. 
difference across the element and $n s$ is the total number of series elements. $P_{k}$ and $\delta_{k}$ are defined for the post-fault network.

The potential energy can be decomposed into the energy within the two areas and the energy along the critical cutset [11]. Assuming coherent areas, the potential energy within an area is zero as all the buses in that area have the same frequency ( $\frac{d \delta_{k}}{\mathrm{~d} t}$ is zero for all series elements within an area). Hence, the potential energy given by Eq. (20) can be written as follows:

$W_{\mathrm{p}}=\sum_{k=1}^{n c} \int_{t_{o}}^{t}\left(P_{k}-P_{k \mathrm{~s}}\right) \frac{\mathrm{d} \delta_{k}}{\mathrm{~d} t} \mathrm{~d} t$

where $n c$ is the number of elements in the critical cutset. If a series element (line or transformer) $k$ in the critical cutset connects buses $i$ and $j$,

$P_{k}=V_{i} V_{j} b_{k} \sin \delta_{k}$

$\delta_{k}=\phi_{i}-\phi_{j}$

where $V_{i}$ and $V_{j}$ are the voltage magnitudes at buses $i$ (in area I) and $j$ (in area II), respectively, and $b_{k}$ is the susceptance of the series element. $\phi_{i}$ and $\phi_{j}$ are phase angles of voltage at buses $i$ and $j$, respectively. Due to the assumption of coherency, the variations of $V_{i}$ and $\phi_{i}$ are similar for all the elements in the critical cutset. This is also true of the variations of $V_{j}$ and $\phi_{j}$. Therefore, the variation of energy in all the lines in the critical cutset is similar. Hence, the variation of potential energy can be monitored from the energy in the individual lines in the cutset. Hence

$W_{\mathrm{p}}=A_{k} \int_{t_{o}}^{t}\left(P_{k}-P_{k \mathrm{~s}}\right) \frac{\mathrm{d} \delta_{k}}{\mathrm{~d} t} \mathrm{~d} t$

where $A_{k}$ is a constant and subscript $k$ refers to any element in the cutset.

The expression for potential energy is similar to that for SMIB system given by Eq. (2). Therefore, the control strategy developed for SMIB system can be extended to the multimachine system also, by replacing $\frac{\mathrm{d} \delta}{\mathrm{d} t}$ by $\frac{\mathrm{d} \delta_{k}}{\mathrm{~d} t}$. In step 2 of the control strategy, $\frac{\mathrm{d} W_{\mathrm{p}}}{\mathrm{d} t}=0$ if $P_{k}=P_{k \mathrm{~s}}$ or $\frac{\mathrm{d} \delta_{k}}{\mathrm{~d} t}=0$.

The power flow considered in the control strategy is that flowing from the area containing the advanced generators to the other area. $\delta_{k}=\phi_{i}-\phi_{j}$, where $\phi_{i}$ is the phase angle of bus $i$ which is in the area containing advanced generators and $\phi_{j}$ is the phase angle of bus $j$ which is in the other area.

The UPFC is represented by a two-port network as shown in Fig. 6.

The external network can be represented by its Thevenin equivalent at the two ports of UPFC. By taking the opencircuit voltage at port 2 as reference, the two-port network equation is as follows:

$$
\left[\begin{array}{c}
E_{1} \angle \zeta \\
E_{2} \angle 0
\end{array}\right]=-\left[\begin{array}{cc}
Z_{1} \angle \theta_{1} & Z_{\mathrm{m}} \angle \theta_{\mathrm{m}} \\
Z_{\mathrm{m}} \angle \theta_{\mathrm{m}} & Z_{2} \angle \theta_{2}
\end{array}\right]\left[\begin{array}{l}
\hat{I}_{l 1} \\
\hat{I}_{l 2}
\end{array}\right]+\left[\begin{array}{l}
\hat{V}_{n 1} \\
\hat{V}_{n 2}
\end{array}\right]
$$

where $E_{1} \angle \zeta$ and $E_{2} \angle 0$ are the open-circuit voltages at the ports 1 and 2 , respectively.

The power flow in the line in which UPFC is located, is given by the following equation:

$$
\begin{aligned}
P_{\mathrm{k}}= & a^{\prime} V^{2}+b^{\prime} I^{2}+c^{\prime} V \cos \phi+d^{\prime} V \sin \phi+f^{\prime} I \cos \psi \\
& +g^{\prime} I \sin \psi+h^{\prime} V I \cos (\psi-\phi) \\
& +k^{\prime} V I \sin (\psi-\phi)+l^{\prime}
\end{aligned}
$$

The real power constraint on the UPFC is given by the following equation:

$$
\begin{aligned}
& m^{\prime} V^{2}+n^{\prime} I^{2}+o^{\prime} V \cos \phi+p^{\prime} V \sin \phi+q^{\prime} I \cos \psi \\
& \quad+r^{\prime} I \sin \psi+s^{\prime} V I \cos (\psi-\phi)+t^{\prime} V I \sin (\psi-\phi)=0
\end{aligned}
$$

The expressions for the coefficients $a^{\prime}$ to $t^{\prime}$ are given in Appendix B.

The expression for power given by Eq. (26) is different from that given by Eq. (3) for the SMIB system. This is because of the following two reasons:

(1) The power considered for the SMIB system is the generator power, whereas for the multimachine system, it is the power at the input port of UPFC.

(2) For the multimachine system, in general $Z_{\mathrm{m}} \angle \theta_{\mathrm{m}}$ is not zero. For the special case in which the line in which UPFC is located, is the only line in the cutset, $Z_{\mathrm{m}} \angle \theta_{\mathrm{m}}=0$.

Therefore, the expressions for power for the SMIB system and the multimachine system are equivalent if $Z_{\mathrm{m}} \angle \theta_{\mathrm{m}}=0$ and the circuit is lossless i.e. $\theta_{1}=\theta_{2}=90^{\circ}$.

The real power constraint given by Eq. (27) is different from that given by Eq. (4) due to the impedance $Z_{\mathrm{m}} \angle \theta_{\mathrm{m}}$.

For optimization of power with UPFC, the open-circuit voltages at the UPFC ports are computed at every step. The optimal values of UPFC control variables $V \angle \phi$ and $I \angle \psi$ are obtained and from these values, the currents $\hat{\boldsymbol{I}}_{l 1}$ and $\hat{\boldsymbol{I}}_{l 2}$ (shown in Fig. 6) are computed. These currents are used in the following network equation to obtain the network voltages:

$[\boldsymbol{Y}] \hat{\boldsymbol{V}}=\hat{\boldsymbol{I}}$

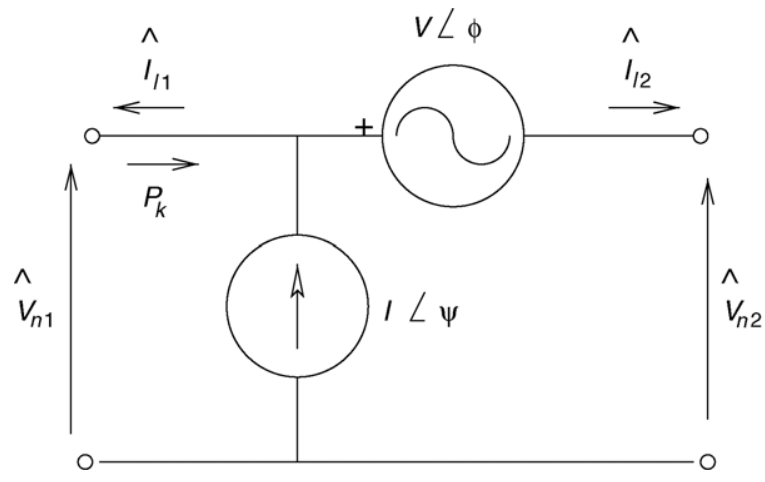

Fig. 6. Equivalent circuit of UPFC. 
where $[\boldsymbol{Y}]$ is the bus admittance matrix, $\hat{\boldsymbol{V}}$ the vector of network voltages and $\hat{\boldsymbol{I}}$ is the vector of currents, which includes generator currents (generator being represented by its Norton's equivalent circuit) and the currents at the UPFC ports.

\section{Simulation studies}

\subsection{SMIB system}

The control strategy is applied to the SMIB system with UPFC, the data for which are given in Appendix C. The generator is represented by two-axis model with static exciter. Since $x_{\mathrm{d}}^{\prime}=x_{\mathrm{q}}^{\prime}$ for the generator considered, an equivalent circuit exists for the generator stator. The network and stator dynamics are neglected. The UPFC is located in transmission line as shown in Fig. 2, such that $X_{1}=X_{2}$. The reactance $X_{1}$ includes the generator direct axis transient reactance $x_{\mathrm{d}}^{\prime}$. The UPFC is represented by series voltage and shunt current sources; the series voltage rating $\left(V_{\max }\right)$ is 0.2 , and the shunt current rating $\left(I_{\max }\right)$ is 0.1 .

The control strategy is applied to this system by creating a large disturbance. The generator is initially supplying power of 0.03 , with its terminal voltage being 1 . The series voltage and shunt current of UPFC are zero in steady state. A step change of 0.69 in the mechanical power input at $0.1 \mathrm{~s}$ is con- sidered as a large disturbance. The system is unstable without any control. The application of the control strategy stabilizes the system as shown in Fig. 7(a); the control is initiated at $0.1 \mathrm{~s}$. System simulation is carried out using Simulink and Matlab optimization toolbox [13] is used to obtain optimum values of the UPFC control variables. Whenever power is to be maximized or minimized, the optimization is to be carried out at each step of the simulation. The optimal values of the control variables obtained at each step are taken as the starting values for optimization at the next step. The analytical solution given in Section 3 for the lossless circuit is taken as the starting value for optimization at the first step of simulation. It is to be noted that the analytical solution given in Section 3 cannot be used directly since $E_{1}$ is not constant and the line resistance is taken into account.

The series reactive and real voltages of the UPFC are plotted in Fig. 7(b). The shunt reactive current of the UPFC is plotted in Fig. 7(c). The real components of the series voltage and the shunt current of UPFC are small compared to their respective reactive components. The power through the dc link of UPFC (power transferred from the series branch to the shunt branch) is shown in Fig. 7(d).

Fig. 8 shows the plot of total system energy. The energy decreases when UPFC control variables are selected so as to maximize or minimize the power. Here the pre-disturbance energy is assumed to be zero. The steady state is reached in about 2 s. This is also evident from Fig. 7(a).
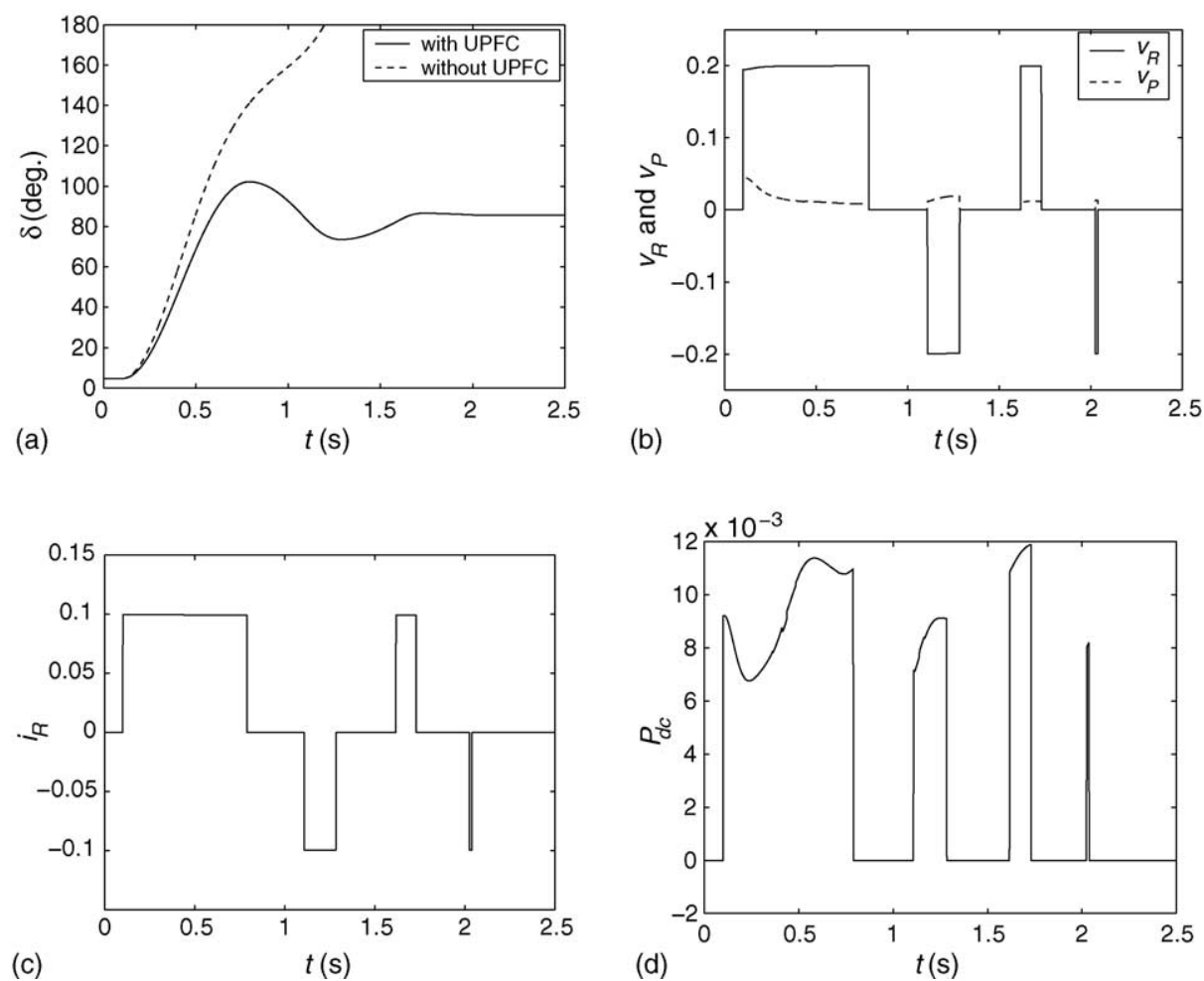

Fig. 7. Response to step change in mechanical power: (a) plot of rotor angle; (b) plot of series reactive and real voltages of UPFC; (c) plot of shunt reactive current of UPFC; (d) plot of power through the de link of UPFC. 


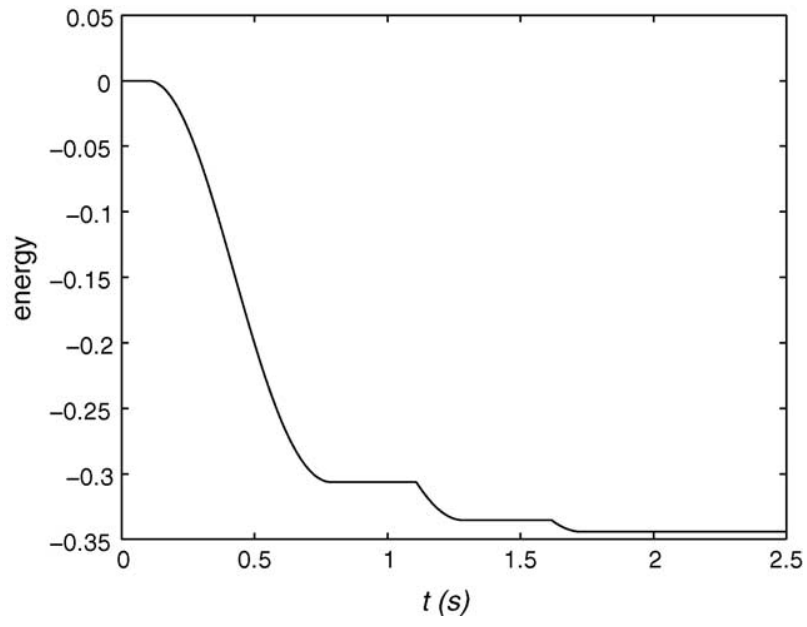

Fig. 8. System energy.

\subsection{Multimachine system}

The control strategy is evaluated by a simulation study on the 10 generator 39 bus New England system. The system data are given in [14]. Fig. 9 shows the single line diagram of the system. The generators are represented by classical model. Loads are assumed to be of constant impedance type. Network losses are ignored.

Fig. 10 shows the swing curves without any control for a fault at bus 34 cleared by tripping the line $34-35$ at $0.267 \mathrm{~s}$. The system is unstable; generator 2 separates from the rest of the system. The lines 11-12 and 18-19 form the critical cutset. The same disturbance is simulated with UPFC at bus

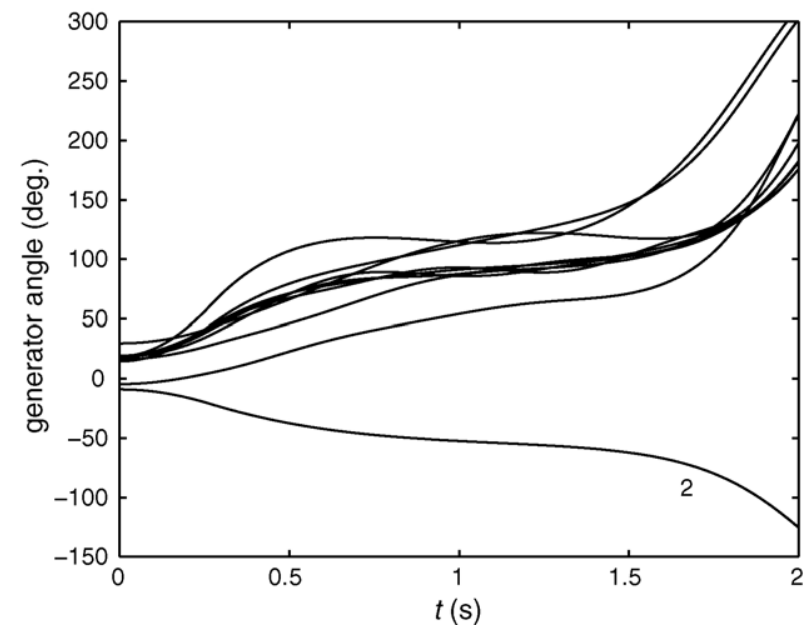

Fig. 10. Swing curves without control.

11 in the lines $11-12$. A rating of 0.2 is used for both series voltage and shunt current of UPFC. It is assumed that UPFC does not inject any voltage or current in steady state. With control initiated at the instant of fault clearing, the system is stable as shown in Fig. 11. Fig. 12 shows the plot of total system energy. Without any control, the system energy in the post-fault period would have been constant due to absence of damping whereas every switching of the UPFC control variables to maximize or minimize the power flow in the line contributes to damping, which can be seen by the decrease in energy during these periods. Fig. 13 shows the plot of power flow in the line 11-12, with and without UPFC. With UPFC, there are discontinuities in the curve due to switchings

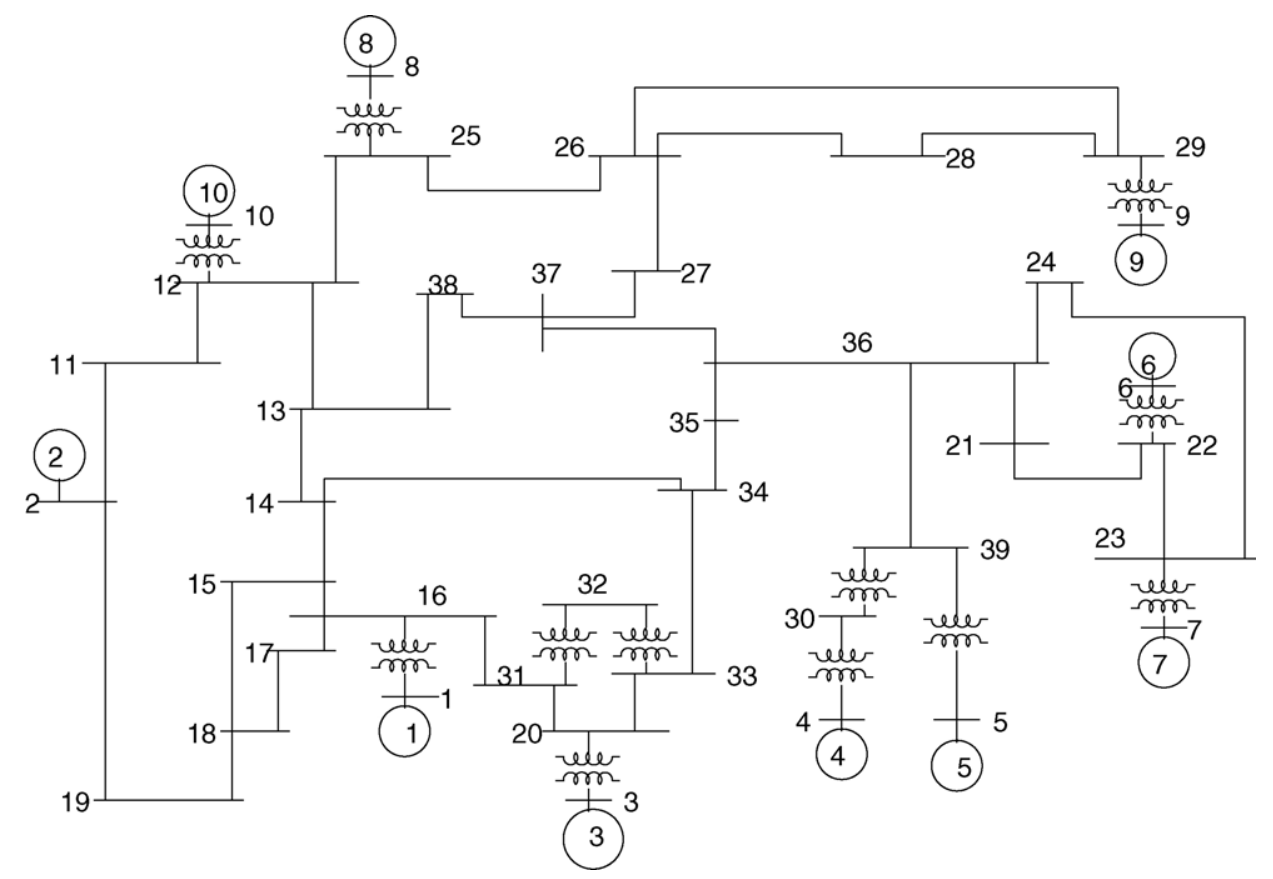

Fig. 9. Single line diagram of 10 generator 39 bus New England system. 


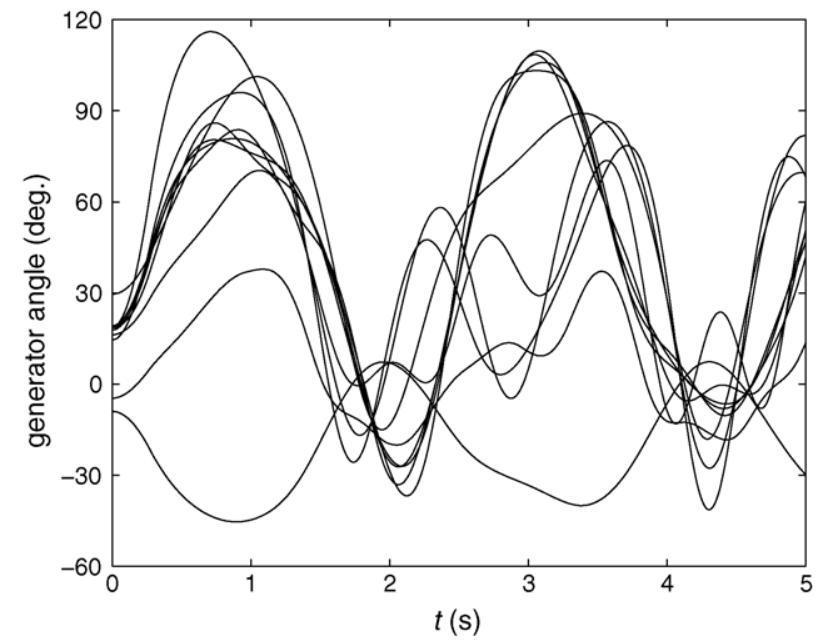

Fig. 11. Swing curves with control action initiated at the instant of fault clearing.

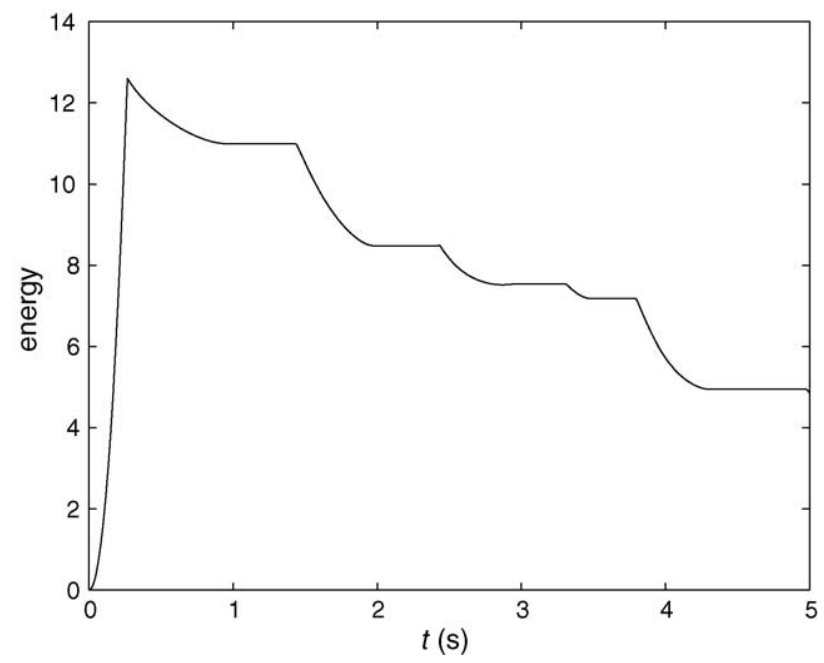

Fig. 12. System energy with control action initiated at the instant of fault clearing.

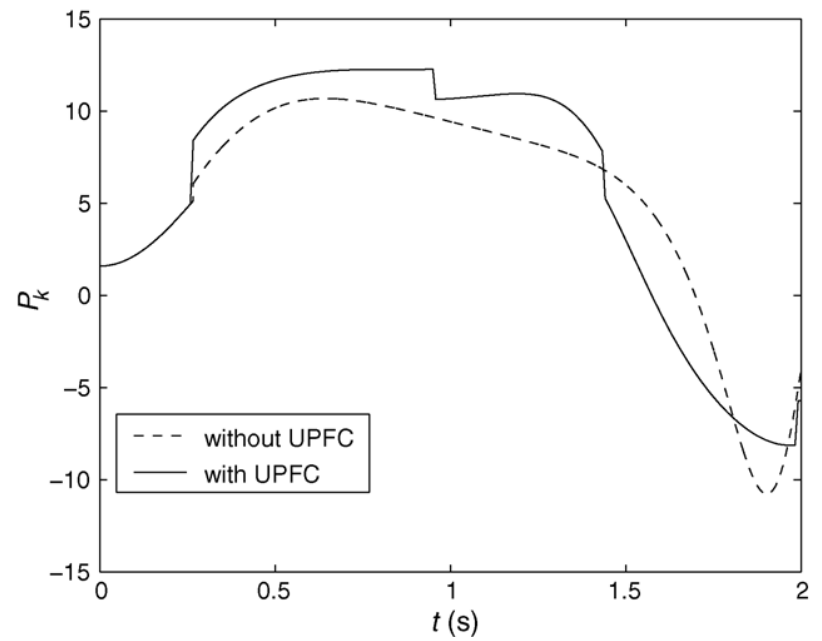

Fig. 13. Power flow in the line 11-12. between base power, maximum power and minimum power. The control variables of UPFC and power through de link of UPFC are shown in Fig. 14.

\section{Discussion}

The UPFC has three independent control variables. The set of independent control variables is not unique. In this paper, the control variables are chosen as the magnitude and angle of the injected series voltage and the magnitude of the shunt current. The constraints on the ratings of the series and the shunt converters can be easily expressed due to the selection of these control variables.

In [4], the control variables are chosen as series voltage magnitude, series voltage angle and effective shunt susceptance. The maximum value of the effective shunt susceptance is assumed as the optimum value in order to maximize power. But unlike in [4], the effective shunt susceptance need not be constant (at the limit) at all values of $\zeta$ as shown in Fig. 15. These curves are obtained for the following values of system parameters: $E_{1}=E_{2}=1, R_{1}=R_{2}=0, X_{1}=X_{2}=0.5$, $V_{\text {max }}=0.5, I_{\max }=0.5$.

When the power through the dc link is constrained to be zero, the optimal magnitudes of the injected voltage and current are not at the limits for large values of $\zeta\left(\zeta\right.$ near $\left.180^{\circ}\right)$ and small values of $\zeta\left(\zeta\right.$ near $\left.0^{\circ}\right)$, respectively, as shown in Fig. 4. This illustrates that for small values of $\zeta$, a SSSC is helpful in increasing the power, whereas for large values of $\zeta$, a STATCOM is more effective.

In a multimachine system, the location of FACTS controllers is an important issue. The location should be based on studies to determine the possible modes of instability for different contingencies. In [11], the TCSC is located in a cutset which separates the system into two areas.

It was found from case studies on the New England 10 generator system, that for many contingencies, the generator at bus 2 separates from the rest of the system because of its large inertia constant. For this mode of instability, the critical cutset consists of the lines 11-12 and 18-19. Therefore, in this paper, the case considered for control is one in which generator 2 separates; UPFC is located in a line belonging to the critical cutset.

Control of UPFC in a multimachine system involves two issues namely the maximization (or minimization) of power and determination of switching instants. For maximization and minimization of power, the knowledge of open-circuit voltages and the Thevenin impedance matrix is required. The values of open-circuit voltages can be obtained from the knowledge of Thevenin impedance matrix using the local measurements of voltage and current at the UPFC ports. In order to determine the instants of switching between base power, maximum power and minimum power, the time derivative of the angle across the line for the postfault system is required; this can be computed from local measurements. 

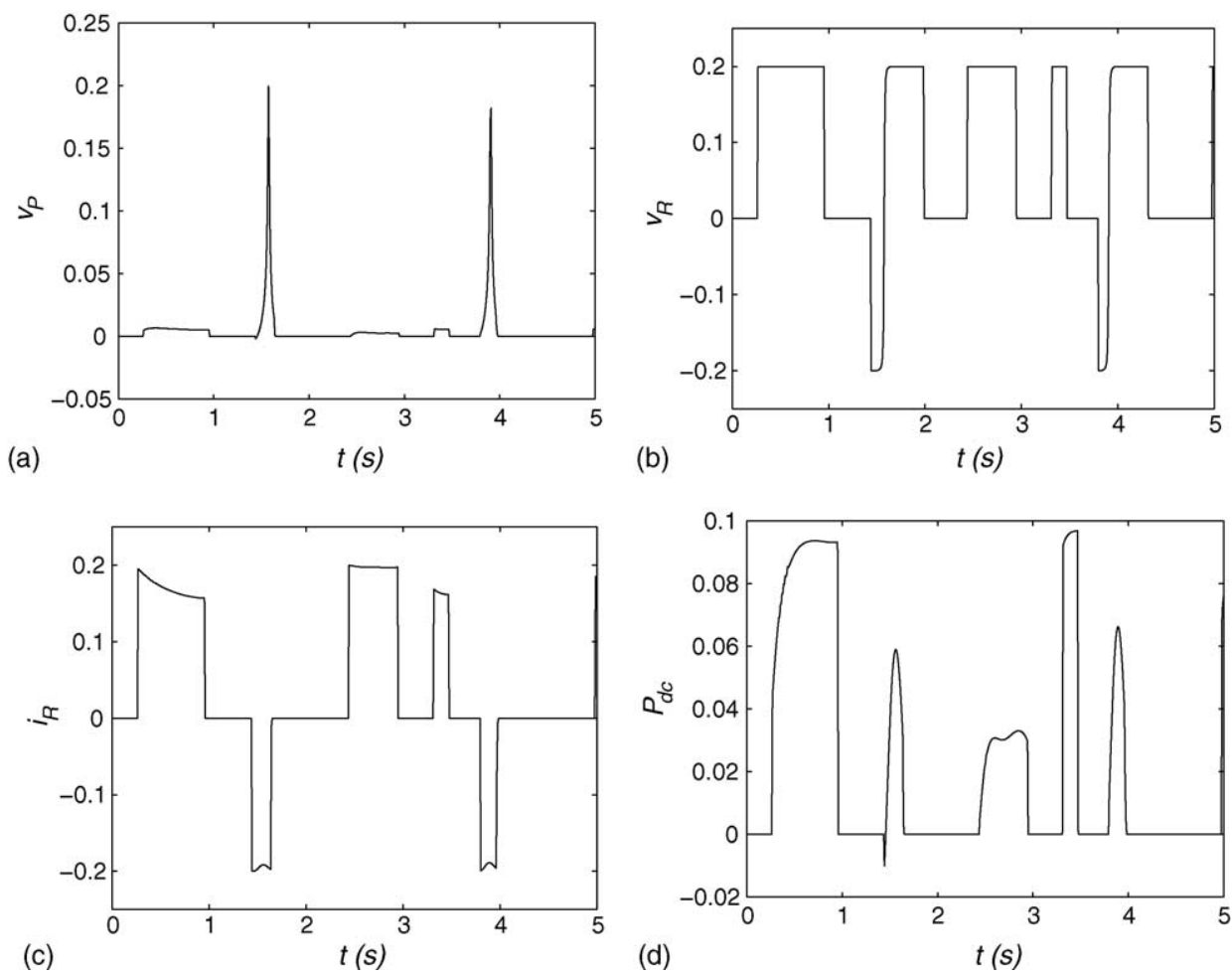

Fig. 14. Control variables of UPFC and power through dc link: (a) plot of series real voltage; (b) plot of series reactive voltage; (c) plot of shunt reactive current; (d) plot of power through the de link.

The control strategy requires the monitoring of the derivative of the potential energy in the line, which is defined for the post-fault system and is given by

$\frac{\mathrm{d} W_{\mathrm{p}}}{\mathrm{d} t}=A_{k}\left(P_{k}-P_{k \mathrm{~s}}\right) \frac{\mathrm{d} \delta_{k}}{\mathrm{~d} t}$

$\frac{\mathrm{d} W_{\mathrm{p}}}{\mathrm{d} t}=0$ if either (i) $P_{k}=P_{k \mathrm{~s}}$ or (ii) $\frac{\mathrm{d} \delta_{k}}{\mathrm{~d} t}=0$. Hence, the control strategy requires only checking of these two conditions. The instant of switching is determined by the condition,

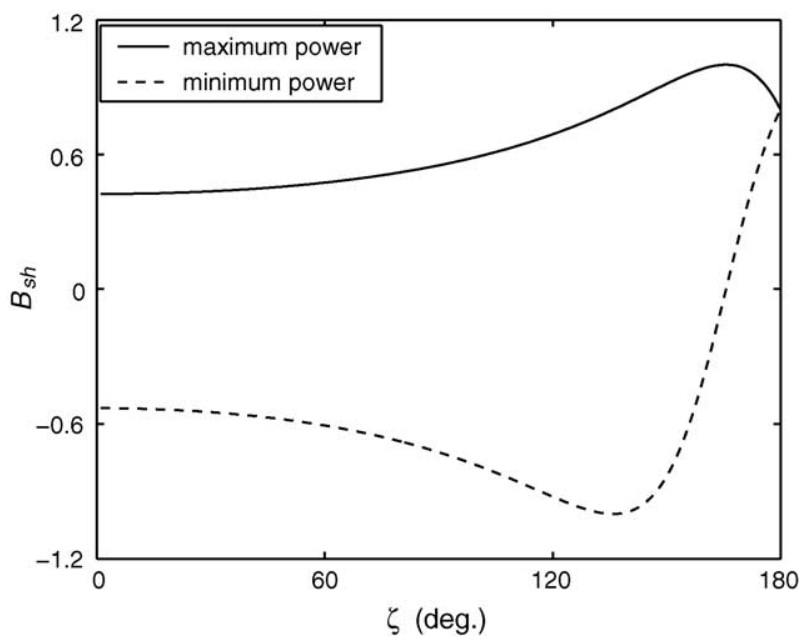

Fig. 15. Effective shunt susceptance of UPFC for maximum and minimum power. which arises first. If a line is tripped in order to clear the fault, the post-fault steady state power in the line $P_{k \mathrm{~s}}$ is different from the pre-fault steady state value $P_{k \mathrm{o}}$. Since the variation of $P_{k}$ is very large compared to $P_{k \mathrm{~s}}$ and $P_{k \mathrm{o}}, P_{k \mathrm{o}}$ can be used instead of $P_{k \mathrm{~s}}$. It was observed from simulation studies that in multimachine system, the switching of the control variables in the second step of the control strategy occurs at the instant when $\frac{\mathrm{d} \delta_{k}}{\mathrm{~d} t}=0$. Therefore, in step 2 of the control strategy for multimachine system, $\frac{\mathrm{d} W_{\mathrm{p}}}{\mathrm{d} t}$ can be replaced by $\frac{\mathrm{d} \delta_{k}}{\mathrm{~d} t}$ and hence, the knowledge of $P_{k \mathrm{~s}}$ is not required.

\section{Conclusion}

Improvement in transient stability and damping of rotor swings can be brought about by selectively operating the UPFC so as to maximize or minimize power flow in the line in which it is located. The proposed control strategy is general and is applicable to any controller, which can affect the power flow in a line. If the UPFC is located at the midpoint of a lossless symmetrical line, analytical solution can be obtained for the control variables in order to maximize and minimize power. The control action in multimachine system can be accomplished using local measurements. Suitable location of UPFC for transient stability improvement can be one of the lines across which the angle becomes unbounded in case of instability; these lines can be identified by simulation studies. The control strategy is validated by system simulation. 


\section{Acknowledgements}

The financial support received from the Department of Science and Technology, Government of India under the project titled "Dynamic Security Assessment and Control of Power Grids" is gratefully acknowledged.

\section{Appendix A. Expression for the coefficients $c$ to $t$}

Let $Z_{1} \angle \theta_{1}=R_{1}+j X_{1}, Z_{2} \angle \theta_{2}=R_{2}+j X_{2}$ and $Z \angle \theta=$ $Z_{1} \angle \theta_{1}+Z_{2} \angle \theta_{2}$.

$c=-\frac{E_{1}}{Z} \cos (\zeta+\theta)$

$d=-\frac{E_{1}}{Z} \sin (\zeta+\theta)$

$f=-\frac{E_{1} Z_{2}}{Z} \cos \left(\zeta-\theta_{2}+\theta\right)$

$g=-\frac{E_{1} Z_{2}}{Z} \sin \left(\zeta-\theta_{2}+\theta\right)$

$$
\begin{aligned}
& l=\frac{E_{1}^{2}}{Z} \cos \theta-\frac{E_{1} E_{2}}{Z} \cos (\zeta+\theta) \\
& m=\frac{1}{Z} \cos \theta \\
& n=\frac{Z_{1} Z_{2}}{Z} \cos \left(\theta_{1}+\theta_{2}-\theta\right) \\
& o=-\frac{E_{1}}{Z} \cos (\zeta-\theta)+\frac{E_{2}}{Z} \cos \theta \\
& p=-\frac{E_{1}}{Z} \sin (\zeta-\theta)-\frac{E_{2}}{Z} \sin \theta \\
& q=\frac{E_{1} Z_{2}}{Z} \cos \left(\zeta+\theta_{2}-\theta\right)+\frac{E_{2} Z_{1}}{Z} \cos \left(\theta_{1}-\theta\right) \\
& r=\frac{E_{1} Z_{2}}{Z} \sin \left(\zeta+\theta_{2}-\theta\right)+\frac{E_{2} Z_{1}}{Z} \sin \left(\theta_{1}-\theta\right) \\
& t=\frac{2 Z_{1}}{Z} \sin \left(\theta_{1}-\theta\right)
\end{aligned}
$$

\section{Appendix B. Expression for the coefficients $a^{\prime}$ to $t^{\prime}$}

$$
\begin{aligned}
& a^{\prime}=\frac{-Z_{1} \cos \theta_{1}+Z_{\mathrm{m}} \cos \theta_{\mathrm{m}}}{Z_{1}^{2}+Z_{2}^{2}+4 Z_{\mathrm{m}}^{2}-4 Z_{2} Z_{\mathrm{m}} \cos \left(\theta_{\mathrm{m}}-\theta_{2}\right)-4 Z_{1} Z_{\mathrm{m}} \cos \left(\theta_{\mathrm{m}}-\theta_{1}\right)+2 Z_{1} Z_{2} \cos \left(\theta_{2}-\theta_{1}\right)} \\
& b^{\prime}=\frac{Z_{2} Z_{\mathrm{m}}^{2} \cos \left(\theta_{2}-2 \theta_{\mathrm{m}}\right)-Z_{\mathrm{m}}^{3} \cos \theta_{\mathrm{m}}-Z_{1} Z_{2}^{2} \cos \theta_{1}+Z_{1} Z_{2} Z_{\mathrm{m}} \cos \left(\theta_{1}+\theta_{2}-\theta_{\mathrm{m}}\right)}{Z_{1}^{2}+Z_{2}^{2}+4 Z_{\mathrm{m}}^{2}-4 Z_{2} Z_{\mathrm{m}} \cos \left(\theta_{\mathrm{m}}-\theta_{2}\right)-4 Z_{1} Z_{\mathrm{m}} \cos \left(\theta_{\mathrm{m}}-\theta_{1}\right)+2 Z_{1} Z_{2} \cos \left(\theta_{2}-\theta_{1}\right)} \\
& c^{\prime}=\frac{\left[E_{1} Z_{\mathrm{m}} \cos \left(\zeta+\theta_{\mathrm{m}}\right)-E_{1} Z_{2} \cos \left(\zeta+\theta_{2}\right)-2 E_{2} Z_{1} \cos \theta_{1}+E_{1} Z_{1} \cos \left(\theta_{1}-\zeta\right)+2 E_{2} Z_{\mathrm{m}} \cos \theta_{\mathrm{m}}-E_{1} Z_{\mathrm{m}} \cos \left(\theta_{\mathrm{m}}-\zeta\right)\right]}{Z_{1}^{2}+Z_{2}^{2}+4 Z_{\mathrm{m}}^{2}-4 Z_{2} Z_{\mathrm{m}} \cos \left(\theta_{\mathrm{m}}-\theta_{2}\right)-4 Z_{1} Z_{\mathrm{m}} \cos \left(\theta_{\mathrm{m}}-\theta_{1}\right)+2 Z_{1} Z_{2} \cos \left(\theta_{2}-\theta_{1}\right)} \\
& d^{\prime}=\frac{E_{1} Z_{\mathrm{m}} \sin \left(\zeta+\theta_{\mathrm{m}}\right)-E_{1} Z_{2} \sin \left(\zeta+\theta_{2}\right)-E_{1} Z_{1} \sin \left(\theta_{1}-\zeta\right)+E_{1} Z_{\mathrm{m}} \sin \left(\theta_{\mathrm{m}}-\zeta\right)}{Z_{1}^{2}+Z_{2}^{2}+4 Z_{\mathrm{m}}^{2}-4 Z_{2} Z_{\mathrm{m}} \cos \left(\theta_{\mathrm{m}}-\theta_{2}\right)-4 Z_{1} Z_{\mathrm{m}} \cos \left(\theta_{\mathrm{m}}-\theta_{1}\right)+2 Z_{1} Z_{2} \cos \left(\theta_{2}-\theta_{1}\right)} \\
& {\left[E_{1} Z_{2} Z_{\mathrm{m}} \cos \left(\zeta+\theta_{\mathrm{m}}-\theta_{2}\right)-E_{1} Z_{\mathrm{m}}^{2} \cos \zeta+E_{2} Z_{\mathrm{m}}^{2} \cos \left(2 \theta_{\mathrm{m}}\right)-E_{1} Z_{\mathrm{m}}^{2} \cos \left(2 \theta_{\mathrm{m}}-\zeta\right)-E_{1} Z_{2}^{2} \cos \zeta\right.} \\
& +E_{1} Z_{2} Z_{\mathrm{m}} \cos \left(\zeta+\theta_{2}-\theta_{\mathrm{m}}\right)-E_{2} Z_{1} Z_{2} \cos \left(\theta_{1}-\theta_{2}\right)+E_{2} Z_{1} Z_{\mathrm{m}} \cos \left(\theta_{1}-\theta_{\mathrm{m}}\right)-E_{2} Z_{1} Z_{2} \cos \left(\theta_{1}+\theta_{2}\right) \\
& f^{\prime}=\frac{\left.+E_{1} Z_{1} Z_{2} \cos \left(\theta_{1}+\theta_{2}-\zeta\right)+E_{2} Z_{2} Z_{\mathrm{m}} \cos \left(\theta_{\mathrm{m}}-\theta_{2}\right)-E_{2} Z_{\mathrm{m}}^{2}\right]}{Z_{1}^{2}+Z_{2}^{2}+4 Z_{\mathrm{m}}^{2}-4 Z_{2} Z_{\mathrm{m}} \cos \left(\theta_{\mathrm{m}}-\theta_{2}\right)-4 Z_{1} Z_{\mathrm{m}} \cos \left(\theta_{\mathrm{m}}-\theta_{1}\right)+2 Z_{1} Z_{2} \cos \left(\theta_{2}-\theta_{1}\right)} \\
& {\left[E_{1} E_{2} Z_{\mathrm{m}} \sin \left(\zeta+\theta_{\mathrm{m}}-\theta_{2}\right)-E_{1} Z_{\mathrm{m}}^{2} \sin \zeta-E_{2} Z_{\mathrm{m}}^{2} \sin \left(2 \theta_{\mathrm{m}}\right)+E_{1} Z_{\mathrm{m}}^{2} \sin \left(2 \theta_{\mathrm{m}}-\zeta\right)-E_{1} Z_{2}^{2} \sin \zeta\right.} \\
& +E_{1} Z_{2} Z_{\mathrm{m}} \sin \left(\zeta+\theta_{2}-\theta_{\mathrm{m}}\right)-E_{2} Z_{1} Z_{2} \sin \left(\theta_{1}-\theta_{2}\right)+E_{2} Z_{1} Z_{\mathrm{m}} \sin \left(\theta_{1}-\theta_{\mathrm{m}}\right)+E_{2} Z_{1} Z_{2} \sin \left(\theta_{1}+\theta_{2}\right) \\
& g^{\prime}=\frac{\left.-E_{1} Z_{1} Z_{2} \sin \left(\theta_{1}+\theta_{2}-\zeta\right)+E_{2} Z_{2} Z_{\mathrm{m}} \sin \left(\theta_{\mathrm{m}}-\theta_{2}\right)\right]}{Z_{1}^{2}+Z_{2}^{2}+4 Z_{\mathrm{m}}^{2}-4 Z_{2} Z_{\mathrm{m}} \cos \left(\theta_{\mathrm{m}}-\theta_{2}\right)-4 Z_{1} Z_{\mathrm{m}} \cos \left(\theta_{\mathrm{m}}-\theta_{1}\right)+2 Z_{1} Z_{2} \cos \left(\theta_{2}-\theta_{1}\right)} \\
& h^{\prime}=\frac{\left[Z_{\mathrm{m}}^{2} \cos \left(2 \theta_{\mathrm{m}}\right)-Z_{1} Z_{2} \cos \left(\theta_{1}+\theta_{2}\right)-Z_{1} Z_{2} \cos \left(\theta_{1}-\theta_{2}\right)+Z_{1} Z_{\mathrm{m}} \cos \left(\theta_{1}-\theta_{\mathrm{m}}\right)+Z_{2} Z_{\mathrm{m}} \cos \left(\theta_{\mathrm{m}}-\theta_{2}\right)-Z_{\mathrm{m}}^{2}\right]}{Z_{1}^{2}+Z_{2}^{2}+4 Z_{\mathrm{m}}^{2}-4 Z_{2} Z_{\mathrm{m}} \cos \left(\theta_{\mathrm{m}}-\theta_{2}\right)-4 Z_{1} Z_{\mathrm{m}} \cos \left(\theta_{\mathrm{m}}-\theta_{1}\right)+2 Z_{1} Z_{2} \cos \left(\theta_{2}-\theta_{1}\right)}
\end{aligned}
$$




$$
\begin{aligned}
k^{\prime}= & \frac{\left[-Z_{\mathrm{m}}^{2} \sin \left(2 \theta_{\mathrm{m}}\right)+Z_{1} Z_{2} \sin \left(\theta_{1}+\theta_{2}\right)-Z_{1} Z_{2} \sin \left(\theta_{1}-\theta_{2}\right)+Z_{1} Z_{\mathrm{m}} \sin \left(\theta_{1}-\theta_{\mathrm{m}}\right)+Z_{2} Z_{\mathrm{m}} \sin \left(\theta_{\mathrm{m}}-\theta_{2}\right)\right]}{Z_{1}^{2}+Z_{2}^{2}+4 Z_{\mathrm{m}}^{2}-4 Z_{2} Z_{\mathrm{m}} \cos \left(\theta_{\mathrm{m}}-\theta_{2}\right)-4 Z_{1} Z_{\mathrm{m}} \cos \left(\theta_{\mathrm{m}}-\theta_{1}\right)+2 Z_{1} Z_{2} \cos \left(\theta_{2}-\theta_{1}\right)} \\
l^{\prime}= & \frac{\left[E_{1} E_{2} Z_{\mathrm{m}} \cos \left(\zeta+\theta_{\mathrm{m}}\right)-E_{1}^{2} Z_{\mathrm{m}} \cos \theta_{\mathrm{m}}-E_{1} E_{2} Z_{2} \cos \left(\zeta+\theta_{2}\right)\right.}{\left.+E_{1}^{2} Z_{2} \cos \theta_{2}-E_{2}^{2} Z_{1} \cos \theta_{1}+E_{1} E_{2} Z_{1} \cos \left(\theta_{1}-\zeta\right)+E_{2}^{2} Z_{\mathrm{m}} \cos \theta_{\mathrm{m}}-E_{1} E_{2} Z_{\mathrm{m}} \cos \left(\theta_{\mathrm{m}}-\zeta\right)\right]} \\
Z_{1}^{2}+Z_{2}^{2}+4 Z_{\mathrm{m}}^{2}-4 Z_{2} Z_{\mathrm{m}} \cos \left(\theta_{\mathrm{m}}-\theta_{2}\right)-4 Z_{1} Z_{\mathrm{m}} \cos \left(\theta_{\mathrm{m}}-\theta_{1}\right)+2 Z_{1} Z_{2} \cos \left(\theta_{2}-\theta_{1}\right) & -\frac{1}{Z} \cos \theta \\
m^{\prime}= & -\frac{Z_{1} Z_{2}}{Z} \cos \left(\theta_{1}+\theta_{2}-\theta\right)+\frac{Z_{\mathrm{m}}^{2}}{Z} \cos \left(2 \theta_{\mathrm{m}}-\theta\right) \\
n^{\prime}= & \frac{E_{1}}{Z} \cos (\zeta-\theta)-\frac{E_{2}}{Z} \cos \theta \\
p^{\prime}= & \frac{E_{1}}{Z} \sin (\zeta-\theta)-\frac{E_{2}}{Z} \sin \theta \\
q^{\prime}= & \frac{E_{1} Z_{\mathrm{m}}}{Z} \cos \left(\zeta+\theta_{\mathrm{m}}-\theta\right)-\frac{E_{1} Z_{2}}{Z} \cos \left(\zeta+\theta_{2}-\theta\right)-\frac{E_{2} Z_{1}}{Z} \cos \left(\theta_{1}-\theta\right)+\frac{E_{2} Z_{\mathrm{m}}}{Z} \cos \left(\theta_{\mathrm{m}}-\theta\right) \\
r^{\prime}= & \frac{E_{1} Z_{\mathrm{m}}}{Z} \sin \left(\zeta+\theta_{\mathrm{m}}-\theta\right)-\frac{E_{1} Z_{2}}{Z} \sin \left(\zeta+\theta_{2}-\theta\right)-\frac{E_{2} Z_{1}}{Z} \sin \left(\theta_{1}-\theta\right)+\frac{E_{2} Z_{\mathrm{m}}}{Z} \sin \left(\theta_{\mathrm{m}}-\theta\right) \\
s^{\prime}= & -\frac{Z_{1}}{Z} \cos \left(\theta_{1}-\theta\right)+\frac{Z_{\mathrm{m}}}{Z} \cos \left(\theta_{\mathrm{m}}-\theta\right)-1+\frac{Z_{\mathrm{m}}}{Z} \cos \left(\theta_{\mathrm{m}}-\theta\right)-\frac{Z_{2}}{Z} \cos \left(\theta-\theta_{2}\right) \\
t^{\prime}= & -\frac{Z_{1}}{Z} \sin \left(\theta_{1}-\theta\right)-\frac{Z_{2}}{Z} \sin \left(\theta-\theta_{2}\right) \\
w &
\end{aligned}
$$

where

$Z \angle \theta=2 Z_{\mathrm{m}} \angle \theta_{\mathrm{m}}-Z_{1} \angle \theta_{1}-Z_{2} \angle \theta_{2}$

\section{Appendix C. SMIB system data}

Data are given on base MVA of 892.4 and base voltage of $500 \mathrm{kV}$. Frequency is $60 \mathrm{~Hz}$.

Generator data: $x_{\mathrm{d}}=1.79, x_{\mathrm{d}}^{\prime}=0.169, T_{\mathrm{do}}^{\prime}=4.3, R_{\mathrm{a}}=$ $0, x_{\mathrm{q}}=1.71, x_{\mathrm{q}}^{\prime}=0.169, T_{\mathrm{qo}}^{\prime}=0.85, H=5, D=0$.

Operating condition: $P_{\mathrm{e}}=0.03, V_{\mathrm{g}}=1$.

AVR data: $K_{\mathrm{E}}=200, T_{\mathrm{E}}=0.05, E_{\mathrm{fdmax}}=6, E_{\mathrm{fdmin}}=-6$.

Transmission line data: $R_{\mathrm{E}}=0.02, X_{\mathrm{E}}=1, E_{\mathrm{b}}=1$.

UPFC data: $I_{\max }=0.1, V_{\max }=0.2$.

\section{References}

[1] N.G. Hingorani, L. Gyugyi, Understanding FACTS: Concepts and Technology of Flexible AC Transmission Systems, IEEE Press, NY, 2000.

[2] L. Gyugyi, Unified power-flow control concept for flexible AC transmission systems, IEE Proc. C 139 (4) (July 1992) 323331.
[3] K.R. Padiyar, A.M. Kulkarni, Control design and simulation of unified power flow controller, IEEE Trans. Power Deliv. 13 (4) (1998) 1348-1354.

[4] R. Mihalic, P. Zunko, D. Povh, Improvement of transient stability using unified power flow controller, IEEE Trans. Power Deliv. 11 (1) (1996) 485-492.

[5] J. Bian, D.G. Ramey, R.J. Nelson, A. Edris, A study of equipment sizes and constraints for a unified power flow controller, IEEE Trans. Power Deliv. 12 (3) (1997) 1385-1391.

[6] IEEE Committee Report, A description of discrete supplementary controls for stability, IEEE Trans. Power Appar. Syst. 97 (1) (January/Februaray 1978) 149-165.

[7] M.L. Shelton, W.A. Mittelstadt, P.F. Winkleman, W.L. Bellerby, Bonneville power administration $1400 \mathrm{MW}$ braking resistor, IEEE Trans. Power Appar. Syst. 94 (2) (1975) 602-611.

[8] O.J.M. Smith, Power system transient control by capacitor switching, IEEE Trans. Power Appar. Syst. 88 (1) (1969) 28-35.

[9] D.N. Kosterev, W.J. Kolodziej, Bang-bang series capacitor transient stability control, IEEE Trans. Power Syst. 10 (2) (1995) 915924.

[10] J. Chang, J.H. Chow, Time-optimal control of power systems requiring multiple switchings of series capacitors, IEEE Trans. Power Syst. 13 (2) (1998) 367-373. 
[11] K.R. Padiyar, K. Uma Rao, Discrete control of series compensation for stability improvement in power systems, Int. J. Electr. Power Energy Syst. 19 (5) (1997) 311-319.

[12] K.R. Padiyar, S. Krishna, On-line detection of loss of synchronism using locally measurable quantities, in: IEEE Transmission and Distribution Conference and Exposition, Atlanta, October, 2001.

[13] The MathWorks Inc., Using Matlab Version 5, 1999.

[14] K.R. Padiyar, Power System Dynamics: Stability and Control, second ed., B.S. Publications, Hyderabad, 2002. 